\title{
INCIDENCE AND RISK FACTORS OF DIABETIC RETINOPATHY AMONG PATIENTS WITH TYPE 2 DIABETES IN A COMMUNITY HOSPITAL, CENTRAL THAILAND
}

Patcharapol Wittayatechakul, Paniti Hanyos, Ram Rangsin, Boonsub Sakboonyarat

Department of Military and Community Medicine, Phramongkutklao College of Medicine, Bangkok, Thailand

\begin{abstract}
Background: Diabetic retinopathy (DR) is one of the ocular complications among patients with type 2 diabetes (T2D) in both developed and developing countries. At present, epidemiological data of DR and the risk factors among patients with T2D especially in Thai community hospitals have been limited. Methods: A retrospective cohort study was conducted between January 1, 2013 and December 31, 2020 to determine the incidence and risk factors of DR among patients with T2D visiting Tha Wung Hospital, Lop Buri Province, central Thailand. DR was determined according to the International Classification of Diseases, Tenth Revision codes in E113 presented in medical records. Multivariate Cox regression analysis was performed to obtain the adjusted hazard ratios (HR) and $95 \%$ confidence interval (CI) of the factors related to DR.
\end{abstract}

Results: A total of 2007 patients with T2D were enrolled in the present study. During the study period, participants $(5.3 \%)$ had a diagnosis of DR; the incidence rate was 0.9 per 100 person-years $(95 \% \mathrm{CI}$; 0.7-1.1). The independent risk factors for DR included $\mathrm{HbA} 1 \mathrm{c} \geq 8 \%$ (adjusted hazard ratio (AHR) $=4.7$, $95 \% \mathrm{CI} ; 2.5-8.7)$, urine albumin $3+(\mathrm{AHR}=2.4,95 \% \mathrm{CI}$; 1.1-5.3 $)$, urine albumin $4+(\mathrm{AHR}=20.3,95 \%$ $\mathrm{CI}$; 2.7-150.9), and a longer distance between residential area $(\mathrm{AHR}=1.3,95 \% \mathrm{CI}$; 1.2-1.4).

Conclusion: Patients with T2D should be encouraged to reach their glycemic control indicated by HbAlc level. Additionally, effective health interventions should be conducted to contribute appropriate access to diabetic care for patients residing in remote areas.

Keywords: Diabetic retinopathy, Community hospital, Thailand, Incidence, Risk factors

J Southeast Asian Med Res 2020; 5(1): 11-20

http://www.jseamed.org

Correspondence to:

Sakboonyarat B, Department of Military and Community Medicine, Phramongkutklao College of Medicine, Bangkok, Thailand

E-mail: boonsub1991@pcm.ac.th

Received: 10 May 2021

Revised: 25 May 2021

Accepted: 7 June 2021 


\section{Introduction}

Diabetic retinopathy (DR) not only affects health and quality of life, but also presents a costly burden to patients with type 2 diabetes (T2D), their family members, communities and public health systems. Estimated DR prevalence was 18.45 to $36.2 \%$, globally; additionally, DR prevalence has increased over the past decade. ${ }^{(1-4)}$ Furthermore, the annual incidence of DR among patients with T2D were $4.0 \%, 5.0 \%, 10.4 \%$ and $12.7 \%$ in Europe, Sweden, the US, and China, respectively. ${ }^{(5-8)}$ Related studies have reported that essential risk factors for DR included duration of T2D diagnosis, history of insulin used $^{(1,2,4)}$, hemoglobin A1C level ${ }^{(1,4,9)}$, high blood pressure $^{(4,9)}$, pulse pressure ${ }^{(10,11)}$ and lengthy distance from home to obtain care. ${ }^{(12)}$ In many countries such as Germany, the cost of DR increased with the severity of DR accounting for $1.5 \%$ of the cost to the public health system in 2002. ${ }^{(13)}$ In the US, people with financial burden were poorly followed up for treatment. ${ }^{(14)}$ Moreover, a rapidly growing rate of diabetes prevalence and complications in India has been observed, leading to an increase in public health issues. ${ }^{(15)}$

However, epidemiological data of DR and the risk factors among patients with T2D especially in Thai community hospitals were limited. Thus, this study collected data from Tha Wung Hospital, Lop Buri Province central Thailand to determine the incidence and risk factors of DR among patients with T2D over the past decade.

\section{Methods}

\section{Study designs and subjects}

A retrospective cohort study was conducted between January 1, 2013 and December 31, 2020 to determine the incidence and risk factors of DR among patients with T2D. The data were retrieved from the electronic medical records of patients with T2D visiting Tha Wung Hospital. Inclusion criteria for this study comprised patients with T2D aged at least 18 years receiving medical treatment at the noncommunicable diseases (NCDs) clinic of Tha Wung Hospital. Any patient presenting a history of retinal complication or receiving a diagnosis of DR by the ophthalmologists before 2013 was excluded. The study was reviewed and approved by the Royal Thai Army Medical Department Institutional Reviewed Board (approval number R197h/63).

\section{Data collection}

A standardized case report form was used to collect data from the electronic medical records, including demographic characteristics, comorbidities and laboratory test results. Collected data included age, sex, distance between residence area and hospital, risk behaviors including smoking and alcohol consumption, systolic blood pressure (SBP), diastolic blood pressure (DBP), fasting plasma glucose (FPG), hemoglobin A1c (HbA1c), low density lipoprotein cholesterol (LDL), diagnosed DR and comorbidities including hypertension (HT) and dyslipidemia (DLP). T2D was defined by Diabetes Care, 2013 as FPG $\geq 126$ $\mathrm{mg} / \mathrm{dL}$ and confirmed by repeat testing at a second visit, or $\mathrm{HbA} 1 \mathrm{c} \geq 6.5 \%$. ${ }^{(16)}$ DR was determined according to the International Classification of Diseases, Tenth Revision Codes in E113, presented in medical records. ${ }^{(17)}$ BMI was calculated as body weight in kilograms divided by height in meters squared. The pulse pressure (PP) was calculated as the difference of SBP and DBP levels.

\section{Statistical analysis}

Data were analyzed using StataCorp, 2021. Stata Statistical Software: Release 17. College Station, TX, USA: StataCorp LLC. Demographic characteristics were presented using descriptive statistics. Categorical data were illustrated as number and percentage while continuous data were illustrated as mean and standard deviation (SD). The incidence rates per 100 person-months of observation were calculated for DR. The person -times of observation of those participants with diagnosed DR were censored at the date of the disease recorded. Multivariate Cox regression analysis was performed to obtain the adjusted hazard ratios (HR) and 95\% confidence interval (CI) of the factors related to DR, and statistical significance was set at $p$-value $<0.05$. 


\section{Results}

A total of 2007 patients with T2D was enrolled in the present study. The enrolled participants were aged $59.0 \pm 11.0$ years. The majority of participants were female $(68.7 \%)$, and one half of enrolled participants had DLP and HT comorbidities. At baseline, almost 20\% of the subjects were current smokers. The average BMI of participants was $26.8 \pm 4.7 \mathrm{~kg} / \mathrm{m}^{2}$. The average of HbAlc level of participants at baseline was $7.4 \pm 1.8 \%$ while one half of those had $\mathrm{HbA} 1 \mathrm{c} \geq 7 \%$. The average distance between the residential area of participants and hospital was $4.8 \pm 4.2 \mathrm{~km}$. The demographic data are presented in Table 1.
During the study period, for participants $(5.3 \%)$ with diagnosed DR; the incidence rate was 0.9 per 100 person-years. (95\% CI; 0.7-1.1). Figure 1 illustrates the cumulative incidence of DR among patients with T2D in relation to HbA1c level $(p<0.001)$. Univariate and multivariate cox regression analyses identifying risk factors for DR are shown in Tables 2 and 3. The independent risk factors for DR included $\mathrm{HbAlc}$ $\geq 8 \%$ (adjusted hazard ratio $(\mathrm{AHR})=4.7,95 \%$ CI; 2.5-8.7), urine albumin 3+ (AHR $=2.4,95 \%$ CI; 1.1-5.3), urine albumin 4+ $(\mathrm{AHR}=20.3,95 \%$ $\mathrm{CI}$; 2.7-150.9), and a longer distance between residential area $(\mathrm{AHR}=1.3,95 \% \mathrm{CI} ; 1.2-1.4)$.

Table 1. Demographic characteristic of participants $(n=2007)$

$\begin{array}{ll}\text { Characteristics } & \text { n (\%) }\end{array}$

\section{Gender}

Male

$628(31.29)$

Female

$1379(68.71)$

Age (year)

$59.0 \pm 11.0$

$<40$

$88(4.38)$

40-59

$\geq 60$

$971(48.38)$

\section{Comorbidities}

Type 2 diabetes (T2D) only $368(18.34)$

T2D with dyalipidemia (DLP) $370(18.44)$

T2D with hypertension (HT) $275(13.70)$

T2D with DLP and HT $994(49.53)$

\section{Current alcohol consumption}

No

$1529(76.34)$

Yes 
Table 1. Demographic characteristic of participants $(n=2007)$ (continue)

\begin{tabular}{|c|c|}
\hline Characteristics & n $(\%)$ \\
\hline \multicolumn{2}{|l|}{ Current smoker } \\
\hline No & $1604(80.04)$ \\
\hline Yes & $400(19.96)$ \\
\hline Body Mass Index $\left(\mathrm{kg} / \mathrm{m}^{2}\right)$ & $26.79 \pm 4.74$ \\
\hline$<18.5$ & $43(2.18)$ \\
\hline $18.5-22.99$ & $355(18.04)$ \\
\hline $23.0-24.99$ & $358(18.19)$ \\
\hline $25.0-29.99$ & $791(40.19)$ \\
\hline$\geq 30.0$ & $421(21.39)$ \\
\hline Fasting blood sugar (mg/dL) & $153.69 \pm 39.54$ \\
\hline HbA1c levels (mg\%) & $7.41 \pm 1.77$ \\
\hline$<7.0$ & $882(50.26)$ \\
\hline $7.0-7.9$ & $402(22.91)$ \\
\hline$\geq 8.0$ & $471(26.84)$ \\
\hline Distance from residential area $(\mathbf{k m})$ & $2.28 \pm 1.82$ \\
\hline
\end{tabular}

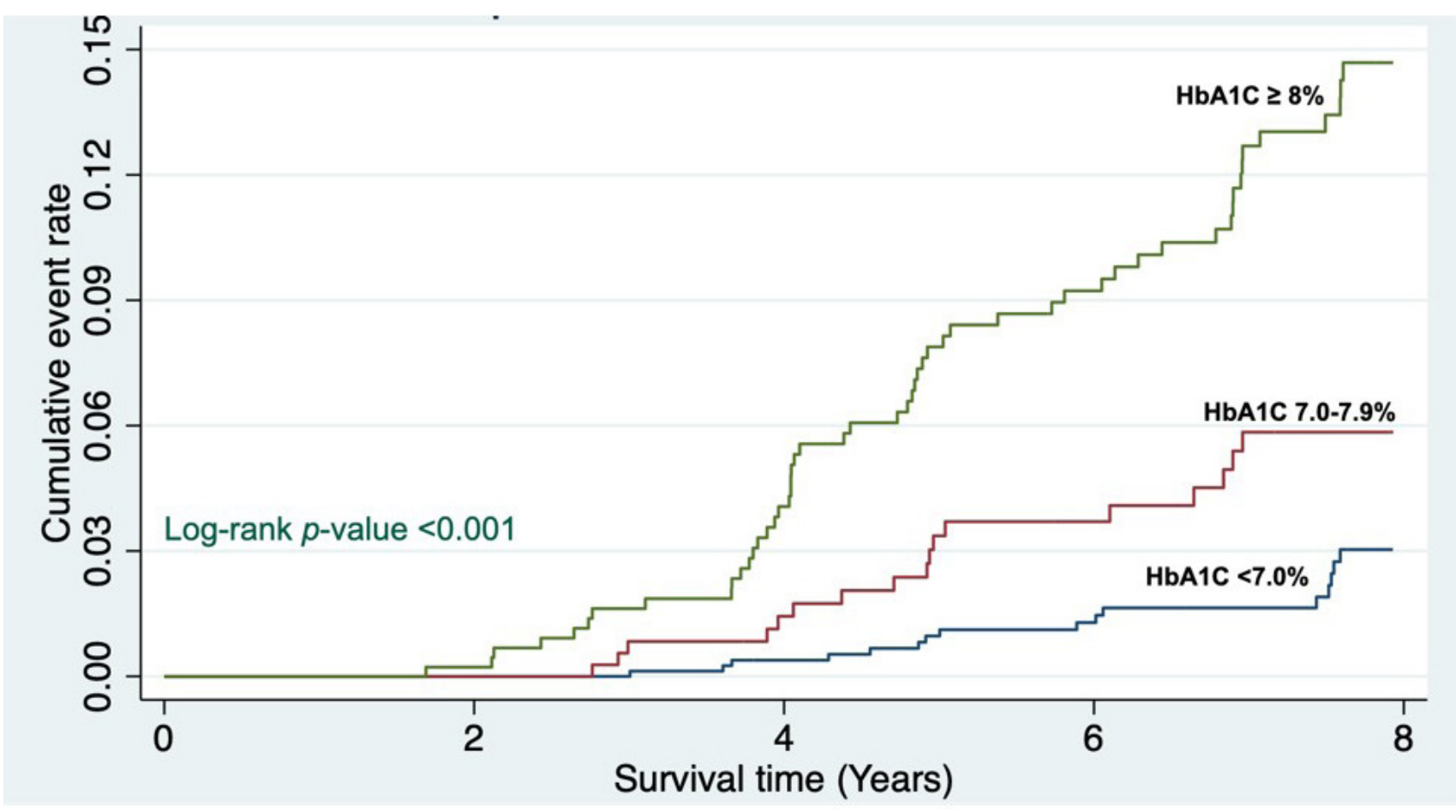

Figure 1. Cumulative incidence of diabetic retinopathy in patients with type 2 diabetes in relation to HbAlc level. 


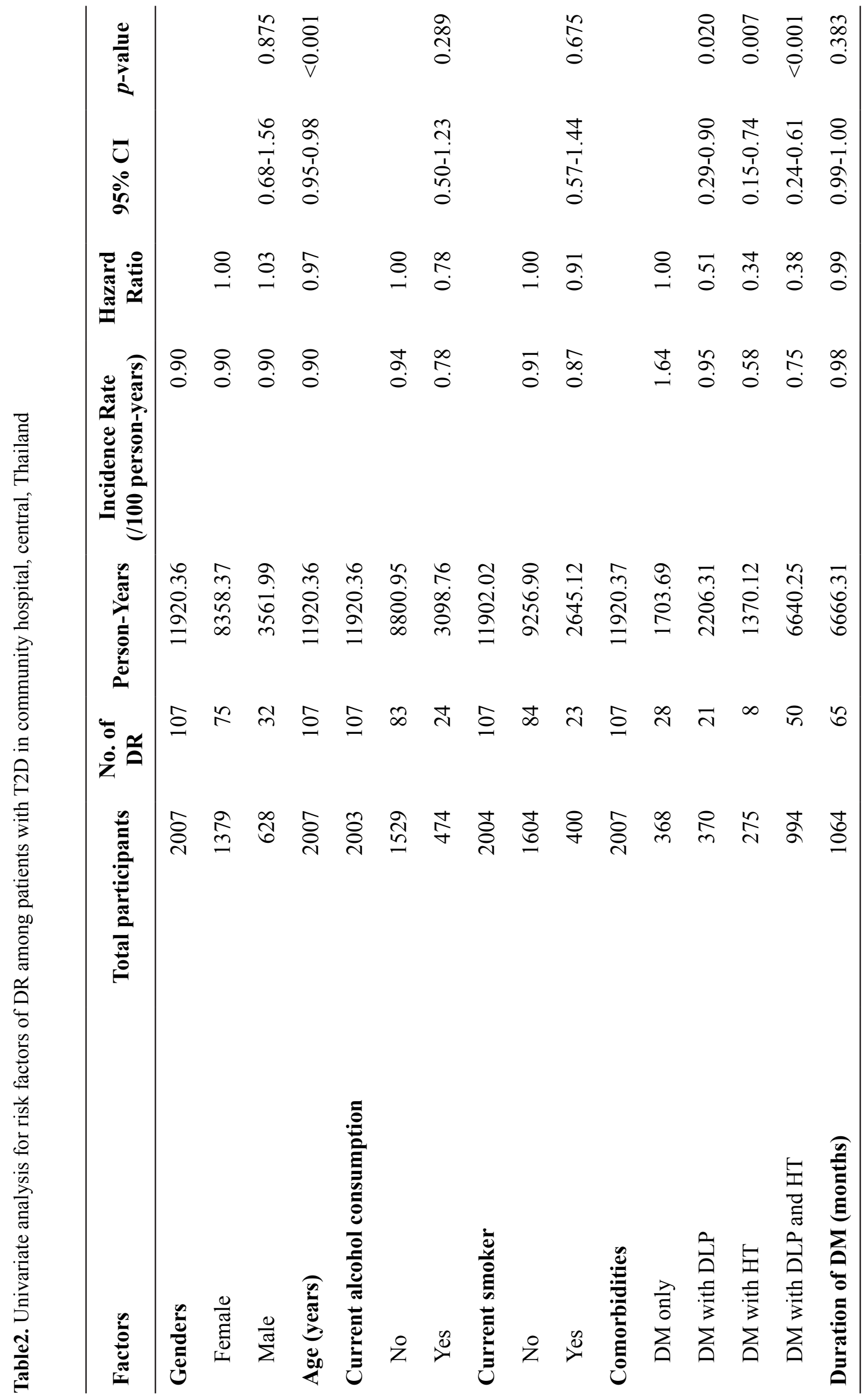




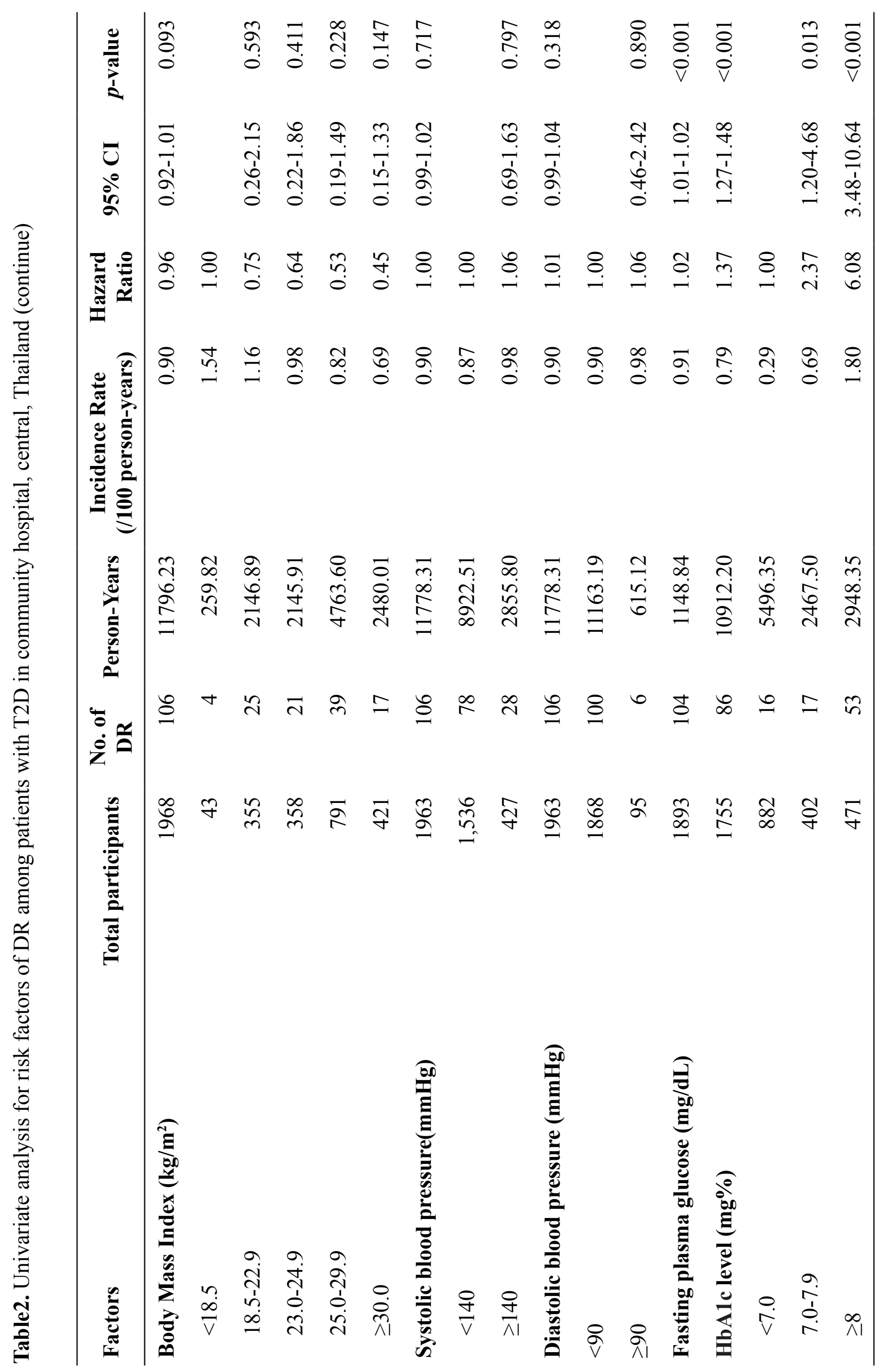


.

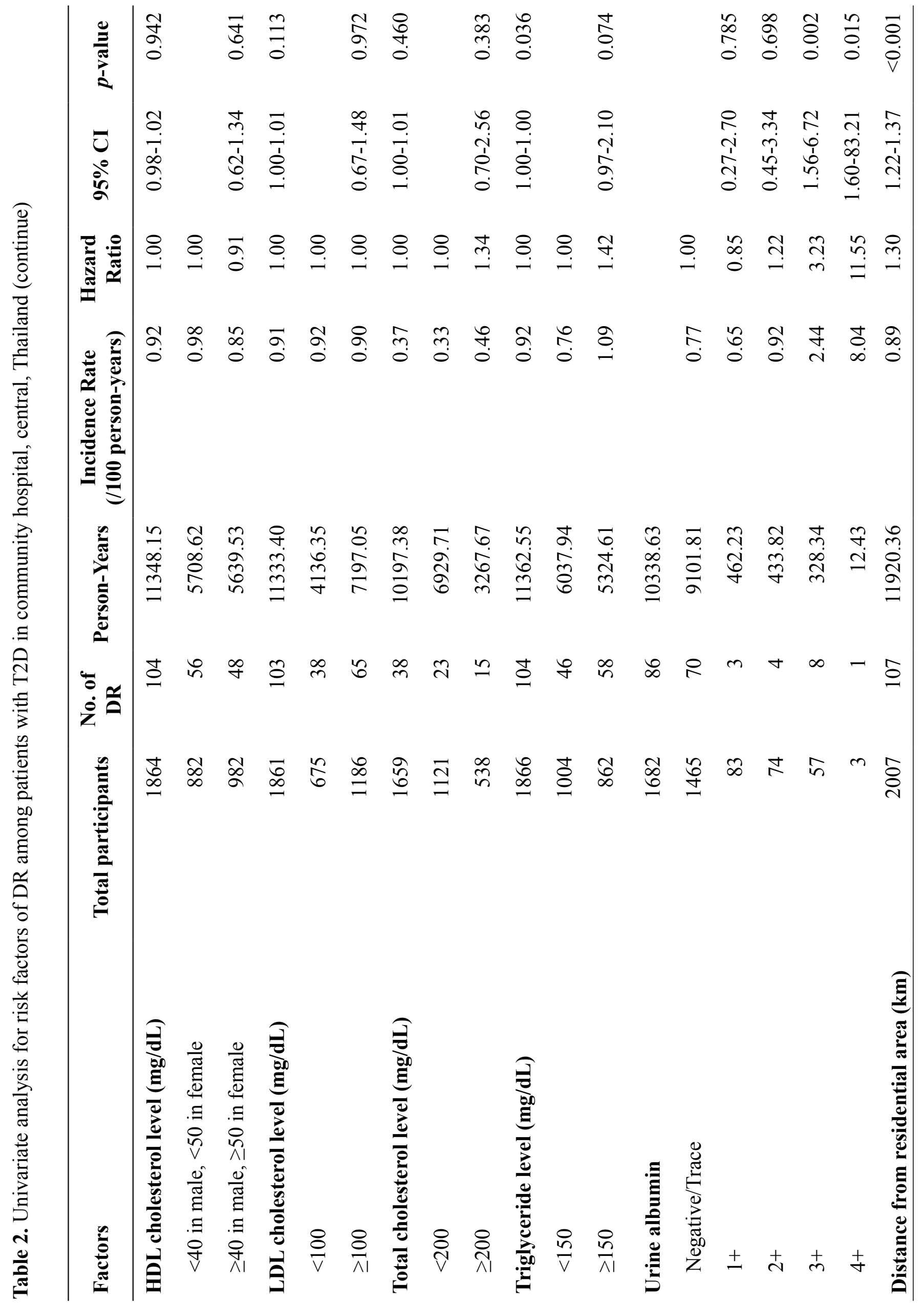


Table 3. Multivariate analysis for risk factors of DR among patients with T2D in community hospital, central, Thailand

\begin{tabular}{lccc}
\hline Factors & $\begin{array}{c}\text { Adjusted Hazard } \\
\text { Ratio }\end{array}$ & $\mathbf{9 5 \%}$ CI & $\boldsymbol{p}$-value \\
\hline Age (years) & 0.98 & $0.96-1.00$ & 0.116 \\
Male vs Female & 1.07 & $0.65-1.76$ & 0.785 \\
Insulin used & 1.25 & $0.68-2.29$ & 0.467 \\
HbA1c level (\%) & & & \\
$\quad<7.0$ & 1 & & \\
$7.0-7.9$ & 1.70 & $0.81-3.59$ & 0.154 \\
$\quad \geq 8$ & 4.70 & $2.54-8.75$ & $<0.001$ \\
Urine albumin & & & \\
$\quad$ Negative/Trace & 1 & & \\
$1+$ & 0.71 & $0.22-2.30$ & 0.581 \\
$2+$ & 0.92 & $0.27-3.06$ & 0.879 \\
$3+$ & 2.42 & $1.11-5.32$ & 0.026 \\
$4+$ & 20.30 & $2.73-150.92$ & 0.003 \\
Distance from residential area (km) & 1.32 & $1.23-1.42$ & $<0.001$ \\
\hline
\end{tabular}

\section{Discussion}

The present study illustrated that the cumulative incidence of DR among patients with T2D was $5.33 \%$ which was comparable with one related report in Thailand. ${ }^{(10)}$ However, compared with the incidences of DR in T2D in other countries, the incidence of those in this study were relatively low. ${ }^{(5-8)}$ Notably, the cumulative incidences of DR stratified by $\mathrm{HbAlc}$ level significantly differed. We found that $\mathrm{HbAlc}$ level $\geq 8 \%$ at the time of enrollment was a potential risk for DR. A related nationwide study in Thailand also indicated that the insulin used was associated with DR. ${ }^{(10)}$ This phenomenon could be explained by prolongated elevated blood sugar level and poorly controlled $\mathrm{HbA} 1 \mathrm{c}$ leading to small vessels injury and occlusion that accompanied abnormal neovascularization resulting in vascular rupture. ${ }^{(18)}$ Our data suggested that effective interventions such as glycemic controlled should be implemented among patients with T2D to alleviate diabetic complications including DR and other cardiovascular complications. The present study reported that insulin used held a positive relationship to the incidence of DR; nevertheless, this was not statistically significant in the final model.

Our finding reported that higher level of urine albumin screened at baseline was an independent risk for DR among patients with T2D. Similarly, related evidence in Brazil demonstrated that proliferative DR was associated with microalbuminuria among patients with T2D. ${ }^{(19)}$ Furthermore, one related study indicated that an increase in albumin creatinine ratio predicted the risk for DR. ${ }^{(20)}$ The laboratory results of diabetic nephropathy could provide information regarding the severity of current diabetes as shown in our analysis. Albuminuria might represent a state of generalized vascular dysfunction that described a higher risk among patients with high urine albuminuria. ${ }^{(21)}$

Our study site represented a community hospital and implied the limited setting of public health care resources. Our study presented that a longer distance between residential area and the hospital was related to risk for DR. One related qualitative study in China indicated that lengthy travel times and transportation barriers may affect the quality of care of patients with T2D, leading to the occurrence of complications. ${ }^{(12)}$ Our data suggested that effective interventions such as fundoscopic exam and teleophthalmology for remote grading should be provided at the community level including primary care units. Further, patients with T2D should be encouraged to receive appropriate care. ${ }^{(22)}$ 
According to secondary data used for analysis, some variables were incomplete. Another limitation was the small sample size in the study; therefore, the association between well-known risk factors such as elevated blood pressure, cholesterol level and outcome could not be presented. The result of our study may not be generalized to the whole country but may reflect the real situation of patients with T2D visiting a Thai community hospital.

\section{Conclusion}

We reported the incidence and risk factors of DR among patients with T2D visiting a community hospital. Patients with T2D should be encouraged to reach their glycemic control indicated by HbA1c level. Additionally, effective health interventions should be conducted to contribute to appropriate access to diabetic care for patients residing in remote areas.

\section{Conflict of interest}

The authors declare they have no conflict of interest.

\section{References}

1. Du ZD, Hu LT, Zhao GQ, Ma Y, Zhou ZY, Jiang -T. Epidemiological characteristics and risk factors of diabetic retinopathy in type 2 diabetes mellitus in Shandong Peninsula of China. Inter J Ophthalmol 2011; 4: 202.

2. Giloyan A, Harutyunyan T, Petrosyan V. The prevalence of and major risk factors associated with diabetic retinopathy in Gegharkunik province of Armenia: cross-sectional study. BMC Ophthalmol 2015; 15: 1-7.

3. Willis JR, Doan QV, Gleeson M, Haskova Z, Ramulu P, Morse L, et al. Vision-related functional burden of diabetic retinopathy across severity levels in the United States. JAMA Ophthalmol 2017; 135: 926-32.

4. Song P, Yu J, Chan KY, Theodoratou E, Rudan I. Prevalence, risk factors and burden of diabetic retinopathy in China: a systematic review and meta-analysis. J Glob Health 2018; 8: 010803.

5. Li JQ, Welchowski T, Schmid M, Letow J, Wolpers C, Pascual-Camps I, et al. Prevalence, incidence and future projection of diabetic eye disease in Europe: a systematic review and meta-analysis. Eur J Epi 2020; 35: 11-23.

6. Henricsson M, Nystrom L, Blohme G, Ostman J, Kullberg C, Svensson M, et al. The incidence of retinopathy 10 years after diagnosis in young adult people with diabetes: results from the nationwide population based diabetes incidence study in Sweden (DISS). Diabetes Care 2003; 26: 349-54.

7. Jin P, Peng J, Zou H, Li M, Li J, Xie SY, et al. The 5 year onset and regression of diabetic retinopathy in Chinese type 2 diabetes patients. PLoS One 2014; 9: e113359.

8. Varma R, Choudhury F, Klein R, Chung J, Torres M, Azen SP, et al. Four year incidence and progression of diabetic retinopathy and macular edema: the Los Angeles Latino Eye Study. Am J Ophthalmol 2010; 149: 752-61. e1-3.

9. Khan R, Singh S, Surya J, Sharma T, Kulothunga V, Raman R. Age of onset of diabetes and its comparison with prevalence and risk factors for diabetic retinopathy in a rural population of India. Ophthalmic Res 2019; 61: 236-42.

10. Euswas N, Phonnopparat N, Morasert K, Thakhampaeng P, Kaewsanit A, Mungthin $M$, et al. National trends in the prevalence of diabetic retinopathy among Thai patients with type 2 diabetes and its associated factors from 2014 to 2018. Plos One 2021; 16: e0245801.

11. Reutrakul S, Deerochanawong C. Diabetes in Thailand: status and policy. Curr Diab Rep 2016; 16: 28.

12. Liu Y, Zupan NJ, Shiyanbola OO, Swearingen R, Carlson JN, Jacobson NA, et al. Factors influencing patient adherence with diabetic eye screening in rural communities: A qualitative study. PLoS One 2018; 13: e0206742.

13. Happich M, Reitberger U, Breitscheidel L, Ulbig M, Watkins J. The economic burden of diabetic retinopathy in Germany in 2002. Graefe's Arch Clin Exp Ophthalmol 2008; 246: 151-9.

14. Peavey JJ, D’Amico SL, Kim BY, Higgins ST, Friedman DS, Brady CJ. Impact of socio economic disadvantage and diabetic retinopathy 
severity on poor ophthalmic follow-up in a rural Vermont and New York population. Clin Ophthalmol 2020 ; 14: 2397-403.

15. Pradeepa R, Mohan V. Prevalence of type 2 diabetes and its complications in India and economic costs to the nation. Eur J Clin Nutr 2017; 71: 816-24.

16. Association AD. Standards of medical care in diabetes-2013. Diabetes Care 2013; 36 (Suppl 1): S11-66.

17. Organization WH. ICD-10: international statistical classification of diseases and related health problems. $10^{\text {th }}$ revision, $5^{\text {th }}$ edition, 2016.

18. Cai J, Boulton M. The pathogenesis of diabetic retinopathy: old concepts and new questions. Eye 2002; 16: 242-60.

19. Boelter MC, Gross JL, Canani LH, Costa LA, Lisboa HR, Três GS, et al. Proliferative diabetic retinopathy is associated with microalbuminuria in patients with type 2 diabetes. Braz J Med Biol Res 2006; 39: 1033-9.

20. Lee MK, Han KD, Lee JH, Sohn SY, Hong OK, Jeong JS, et al. Normal-to-mildly increased albuminuria predicts the risk for diabetic retinopathy in patients with type 2 diabetes. Sci Rep 2017; 7: 1-8.

21. Rani PK, Raman R, Gupta A, Pal SS, Kulothungan V, Sharma T. Albuminuria and diabetic retinopathy in type 2 diabetes mellitus Sankara Nethralaya Diabetic Retinopathy Epidemiology and Molecular Genetic Study (SN-DREAMS, report 12). Diabetol Metab Syndr 2011; 3: 1-8.

22. Vujosevic S, Aldington SJ, Silva $P$, Hernández C, Scanlon P, Peto T, et al. Screening for diabetic retinopathy: new perspectives and challenges. Lancet Diabetes Endocrinol 2020; 8: 337-47. 